\title{
Las pandorgas a través de sus fuentes: música estudiantil en el mundo hispánico a inicios de la Edad Moderna ${ }^{1}$.
}

\section{Pandorgas through their Sources: Student Music in the Hispanic World during the Early Modern Age}

El término pandorga es definido en el diccionario de Covarrubias (1611) como "una consonancia medio alocada, y de mucho ruido que resulta de variedad de instrumentos". Numerosas relaciones de sucesos en el mundo ibérico desde inicios de la Edad Moderna hacen referencia a la participación de estudiantes en ceremonias urbanas organizando pandorgas, consistentes en desfiles con disfraces burlescos en los que se tocaban instrumentos para hacer "ruido" y expresar alegría. Posteriormente, géneros teatrales como la mojiganga se acompañaban de ruidosos "instrumentos de pandorga". Este trabajo analiza, desde una perspectiva musicológica, crónicas, letras de villancicos y textos teatrales, con el propósito de imaginar la música no escrita que sonaba en una pandorga, clarificar los significados cambiantes del término y evaluar el rol de las pandorgas de estudiantes en el ceremonial urbano.

Palabras clave: pandorga, música estudiantil, música y ceremonia, música y teatro, temprana Edad Moderna.

The term pandorga is defined at the Covarrubias dictionary of 1611 as "a crazy consonance with lot of noise resulting from a variety of musical instruments". Numerous accounts of celebrations in the early modern Iberian world refer to the sounding participation of students by organising pandorgas, which consisted of burlesque masquerade parades in which several musical instruments were played in order to make noise and express joy along the city streets. Later on, theatrical genres such as the mojiganga were said to be accompanied by noisy "pandorga instruments". This paper studies, from a musicological perspective, a variety of chronicles, lyrics of villancicos and theatrical texts, with the aim of (1) imagining the non-written music that sounded in a pandorga, (2) clarifying the changing meanings of the word, and (3) assessing the role that students' pandorgas had in the urban soundscape in the early modern Iberian world.

Keywords: Pandorga, students' music, music and ceremony, music and theatre, early Modern age.

Numerosas relaciones de sucesos en el mundo ibérico desde inicios de la Edad Moderna hacen referencia a la participación de estudiantes en ceremonias urbanas organizando pandorgas, consistentes en desfiles con disfraces

\footnotetext{
${ }^{1}$ Una versión previa de este trabajo se presentó en el workshop "Música y Ceremonial", organizado por la Comisión de Trabajo Música y Ceremonial de la Sociedad Española de Musicología, celebrado en la Biblioteca Histórica de la Universidad Complutense de Madrid el 29-3-2019.
} 
burlescos en los que se tocaban instrumentos para hacer "ruido" y expresar alegría por las calles de la ciudad. Las pandorgas de estudiantes eran esenciales en celebraciones como las fiestas de beatificación y canonización, en las que se producía una simbiosis entre lo religioso y lo profano. En su Diccionario de música (1818), Fernando Palatín definía pandorga como una "reunión de muchos instrumentos, de que resulta consonancia de mucho ruido" . A finales del siglo XIX, Felip Pedrell ya calificaba el término de "anticuado" y lo definía como el "concierto de diversos instrumentos que meten mucho ruido y no se tocan acordes"3. Remitía, además, a la voz gatatumba, que describía como una "simulación de obsequio, fiestas, verbena, etc., de reverencia y también de dolor u otra cosa semejante". En su definición de gatatumba, Pedrell citaba, además, un romance de Lope de Vega:

La voz gatatumba nos recuerda el romance de burlas a San Juan Bautista que Lope de Vega escribió para una de tantas festividades eclesiásticas, cuyas últimas coplas dicen así:

Pero, Juan, quedaos con Dios, que desde valle se juntan a celebrar vuestra noche, entre verbenas y murtas, los panderos de Madrid, las sonajas de Setúbar [Setúbal], los cascabeles de Yepes, las gaitas de La Coruña, los adufes de Guinea, las castañetas de Murcia, los relinchos de La Sagra, los tamboriles de Asturias. los salterios de Valencia, las flautas de Cataluña, y en las calles de Sevilla Pandorgas y gatatumbas ${ }^{4}$.

Una definición de pandorga casi idéntica a la de Pedrell se encuentra en el Diccionario de la música (1899) de Luisa Lacal ${ }^{5}$.Ya en el siglo XX, en un glosario de "Instrumentos de música popular española" (1947), José Antonio Donostia incluía la voz pandorga identificándola con la zambomba y

\footnotetext{
${ }^{2}$ Fernando Palatín: Diccionario de música (Sevilla, 1818), Ángel Medina (ed.), Oviedo, Universidad de Oviedo, 1990, p. 81.

${ }^{3}$ Felip Pedrell: Diccionario técnico de la música, Barcelona, Isidro Torres Oriol, [1894] (2. a ed.), p. 346.

${ }^{4}$ Ibid., p. 198. En los textos citados en este artículo se ha actualizado la ortografía y se ha mantenido la puntuación original.

${ }^{5}$ Luisa Lacal de Bacho: Diccionario de la música: técnico, histórico, bio-bibliográfico, Madrid, Establecimiento tipográfico de San Francisco de Sales, 1900 [1899], p. 389: "Anticuado: conjunto de instrumentos que meten mucho ruido, pero no tocan acordes".
} 
añadiendo lo siguiente: "También tiene la significación de baile, pero ordinariamente quiere decir un conjunto más o menos confuso, más o menos mezclado de diversos ruidos o instrumentos" ". En el Diccionario de la música española e hispanoamericana, María José Ruiz Mayordomo define la pandorga como una danza de la que no se tiene descripción coreográfica y que se acompañaba de "una agrupación anárquica de sonidos producidos por un grupo de instrumentos sin ninguna coordinación"”.

El Nuevo diccionario histórico del español recoge veinte acepciones de pandorga, además de locuciones y unidades fraseológicas que incluyen este término. Más allá de sus significados musicales, pandorga se ha utilizado para denominar a una cometa, un juego antiguo en que se utilizaba una lanza para golpear una figura (a la que también se llamó pandorga), un juego de naipes, "una explicación o discurso pesado, torticero o fastidioso", una "burla o broma humillante, grosera y ofensiva", un instrumento de pesca, un abdomen abultado, una mujer gruesa, o una "persona que tiene poca inteligencia o poco entendimiento", entre otras acepciones ${ }^{8}$. El presente artículo sintetiza los resultados de un análisis de crónicas, letras de villancicos y textos teatrales, entre otras fuentes, con el propósito de clarificar los cambios semánticos de las acepciones musicales del término pandorga desde inicios de la Edad Moderna, y de vislumbrar la música no escrita que sonaba en las pandorgas de estudiantes, los instrumentos musicales utilizados, y el rol de estas en el ceremonial urbano.

\section{Instrumentos de pandorga y música no escrita}

Pandorga procede de pandoura, un instrumento de cuerda pulsada con mástil y trastes de la Antigüedad griega y término que derivó en el latín pandura, del que proviene bandurria (Ilustración 1$)^{9}$. La identificación del pandoura dio

\footnotetext{
${ }^{6}$ José Antonio Donostia: "Instrumentos de música popular española", Anuario Musical, 2, 1947, pp. 105-148; 148.

${ }^{7}$ María José Ruiz Mayordomo: "Pandorga", Diccionario de la música española e hispanoamericana (en adelante DMEH), Emilio Casares Rodicio (dir.), Madrid, SGAE, 1999-2002, vol. 8, pp. 434-435.

${ }^{8}$ Real Academia Española: Nuevo diccionario histórico del español (NDHE), (http://web.frl.es/DH, consulta 19-9-2019).

${ }^{9}$ Pierre Chantraine: Dictionnaire étymologique de la langue grecque. Histoire des mots, París, Klincksieck, 1968, p. 855; Émilia Masson: Recherches sur les plus anciens emprunts sémitiques en grec, Études et commentaires 67, París, Klincksieck, 1967, pp. 90-91; Martha Maas, Jane McIntosh Snyder: Stringed Instruments of Ancient Greece, New Haven, Yale University Press, 1989, pp. 185-186; Martin L. West: Ancient Greek Music, Clarendon Press, 1992, p. 80; Thomas J. Mathiesen: Apollo's Lyre: Greek Music and Music Theory in Antiquity and the Middle Ages, Lincoln-Londres, University of Nebraska Press, 1999, pp. 283-285. Véase también Cecilia Criado Boado: "El cambio semántico de pandura", Cada palabra pesaba, cada palabra medía: homenaxe a Antón Santamarina, Mercedes Brea López, Francisco Fernández Rei, Xosé Luís Regueira Fernández (coords.), Santiago de Compostela, Universidad de Santiago de Compostela, 2008, pp. 95-104.
} 


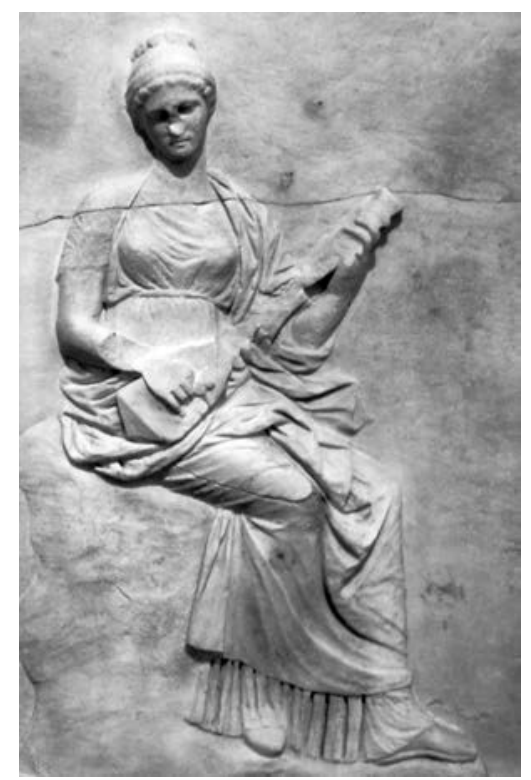

Ilustración 1. Musa tañendo un pandoura, en un pedestal esculpido a mediados del siglo IV a.C. Atenas, Museo Arqueológico Nacional ${ }^{10}$.

Cuadro 1. Primera acepción y significados musicales de pandorga en el Mapa de Diccionarios Académicos de la Real Academia Española (simplificado)

\begin{tabular}{|c|c|c|}
\hline 1737 & $\begin{array}{l}\text { Junta de variedad de instrumentos, de que resulta conso- } \\
\text { nancia de mucho ruido. Dícese por corrupción de Pan- } \\
\text { dora, voz Griega. Latín. Musicorum conjunctum, varietas. }\end{array}$ & \\
\hline 1780 & $\begin{array}{l}\text { Junta de variedad de instrumentos, de que resulta conso- } \\
\text { nancia de mucho ruido. Musicorum conjunctum, varietas. }\end{array}$ & \\
\hline 1817 & $\begin{array}{l}\text { Reunión de muchos instrumentos, de que resulta conso- } \\
\text { nancia de mucho ruido. Musicorum conjunctum, varietas. }\end{array}$ & \\
\hline 1884 & $\begin{array}{l}\text { Figurón que en cierto juego antiguo servía de blanco a } \\
\text { las lanzas de los que pasaban a caballo a la carrera, y suce- } \\
\text { día a veces que el figurón, girando muy rápidamente } \\
\text { sobre su eje, volvía y daba con su brazo al caballero. }\end{array}$ & Murc. Zambomba. \\
\hline 1925 & $\begin{array}{l}\text { Figurón a modo de estafermo, que en cierto juego anti- } \\
\text { guo daba con el brazo al jugador poco diestro. }\end{array}$ & Murc. Zambomba, $1 .^{a}$ acep. \\
\hline 1992 & $\begin{array}{l}\text { Figurón a modo de estafermo, que en cierto juego anti- } \\
\text { guo daba con el brazo al jugador poco diestro. }\end{array}$ & Murc. Zambomba, instrumento músico. \\
\hline 2001 & $\begin{array}{l}\text { Figurón a modo de estafermo, que en cierto juego anti- } \\
\text { guo daba con el brazo al jugador poco diestro. }\end{array}$ & $\begin{array}{l}\text { Mur. zambomba } \\
\text { (instrumento musical). }\end{array}$ \\
\hline
\end{tabular}

${ }^{10}$ Para una descripción de esta figura, véanse R. A. Higgins, Reginald Pepys Winnington-Ingram: "Lute-Players in Greek Art", The Journal of Hellenic Studies, 85, 1965, pp. 62-71; y T. J. Mathiesen: Apollo's Lyre, pp. 283-284. 
lugar a confusión entre los eruditos latinos; Casiodoro en sus Instituciones lo consideraba como un instrumento de viento y, basándose en esta descripción, Isidoro de Sevilla lo asoció al dios Pan en el tercer libro de sus Etimologías ${ }^{11}$. En su diccionario de 1611, Sebastián de Covarrubias definía pandorga como "una consonancia medio alocada, y de mucho ruido que resulta de variedad de instrumentos" ${ }^{\prime 2}$. En efecto, en relaciones de sucesos y crónicas, las pandorgas de estudiantes se asocian a conceptos como disonancia, ruido, música desafinada, bullicio, mascaradas, lo satírico y lo burlesco.Todavía en el Diccionario de la Real Academia Española de 1817, la primera acepción de pandorga continúa siendo la de "reunión de muchos instrumentos, de que resulta consonancia de mucho ruido". A finales de ese siglo, la primera acepción de pandorga pasó a ser un tipo de estafermo utilizado en juegos caballerescos y se conservó un significado musical del término, de carácter regional, como "zambomba" en Murcia $(\text { Cuadro } 1)^{13}$. En portugués, pandorga se continúa relacionando con el desorden y se define como música ruidosa, desafinada y desacompasada.

En España, las pandorgas, con diferentes significados, todavía forman parte de las fiestas folclóricas regionales y generalmente se asocian a un componente ruidoso. "Ciudad Real vivió una noche de Pandorga alegre, ruidosa y sin incidentes" o "Una noche de Pandorga muy ruidosa pero sin incidentes" son titulares de diarios locales en relación a la Pandorga de Ciudad Real, una fiesta de Interés Turístico Regional en la que destaca la figura del Pandorgo, elegido de entre los campesinos para liderar la fiesta ${ }^{14}$. Su punto culminante tiene lugar el 31 de julio con el desfile de los distintos grupos y peñas de la ciudad ataviados con trajes regionales que discurre desde la Plaza Mayor hasta la Catedral, donde se hacen ofrendas a laVirgen del Prado en agradecimiento por la cosecha del año. En Santa Cruz de La Palma, uno de los estadios

${ }^{11}$ Roger. A. B. Mynors (ed.): Cassiodori Senatoris Institutiones, Oxford, The Clarendon Press, 1937, p. 144; W. M. Lindsay (ed. y trad.): Isidori Hispalensis Episcopi Etymologiarum sive Originum Libri XX, Oxford, The Clarendon Press, 1911, vol. 1, libro III. 21. Véanse James W. McKinnon: "Pandoura", Grove Music Online, (https://www.oxfordmusiconline.com/grovemusic/view/10.1093/gmo/9781561592630.001.0001/omo9781561592630-e-0000020802, consulta 22-7-2019): "[...] There was considerable confusion, particularly among later authors, about the identification of the pandoura. Cassiodorus and Isidore of Seville described it as a wind instrument invented by the god Pan [...]"; y Anne-Emmanuelle Ceulemans: "Instruments Real and Imaginary: Aaron's Interpretation of Isidore and an Illustrated Copy of the Toscanello", Early Music History, 21, 2002, pp. 1-35; 16. La errónea identificación del pandoura con un instrumento de viento fue reiterada por autores italianos de los siglos XVIII y XIX, como Giambattista Martini y Niccolò Tommaseo; véase A.-E. Ceulemans: "Instruments Real and Imaginary", p. 16, n. 52.

${ }^{12}$ Sebastián de Covarrubias: Tesoro de la lengua castellana o española, Madrid, Luis Sánchez, 1611, f. 576v.

${ }^{13}$ Manuel Garrido Palacios: "Canciones de pandorga o de zambomba", Revista de Folklore, 159, 1994, pp. 90-92. Según el Nuevo diccionario histórico del español, el término pandorga como sinónimo de zambomba ya se documenta en la comedia burlesca Céfalo y Pocris (c. 1651) de Calderón de la Barca. Véase Pedro Calderón de la Barca: Novena parte de Comedias de Don Pedro Calderón de la Barca que nuevamente corregidas, publica Don Juan de Vera Tassis y Villarroel, Madrid, Francisco Sanz, 1691.

${ }^{14}$ Rafael Cantero Muñoz: La Pandorga: tradición y leyenda, Ciudad Real, Lozano, 2002. 
de las Fiestas Lustrales de la Bajada de la Virgen de las Nieves es la Pandorga, un desfile de luminarias en el que los jóvenes desempeñan un papel fundamental ${ }^{15}$. Fátima Bethencourt señala que la Pandorga apareció en Santa Cruz de La Palma a finales del siglo XVII, "protagonizada desde entonces por los niños, quienes en un desfile nocturno y efimero de cautivadora sencillez, portan múltiples farolillos de diversas formas y colores, destinados a arder en una hoguera final"16. En Auñón (Guadalajara), una pandorga tiene lugar el Domingo de Resurrección, que consistía ya en el siglo XVII en un desfile ruidoso con músicos, sufragado por la Cofradía de la Vera Cruz para despertar a las gentes y anunciarles la resurrección de Jesucristo ${ }^{17}$.

\section{Finales de pandorga y música escénica}

En el siglo XVII encontramos el término pandorga asociado a un "grupo de instrumentos populares y especialmente ruidosos" (Cuadro 2). Estos instrumentos eran frecuentes no solo en el ceremonial festivo, sino también en las representaciones escénicas ${ }^{18}$. En numerosas fuentes teatrales encontramos referencias a los llamados "instrumentos de pandorga". Por ejemplo, en la memoria de las cuentas relativas a los entremeses representados por dos compañías de teatro para las fiestas del Corpus de 1662 se incluye una partida por "una botarga guarnecida de todos estramentos [sic] de pandorga" 19 . María Asunción Flórez indica que la mojiganga, una breve pieza teatral de tono cómico que se representaba en el entreacto o al final de una comedia, se caracterizaba "por una sonoridad propia debida a la utilización de un grupo de instrumentos ruidosos que reciben el nombre de pandorga" ${ }^{20}$. En las representaciones teatrales también se incluyen las pandorgas como un tipo de fin de fiesta, al igual que la mojiganga ${ }^{21}$. El entremés Las carnestolendas y la mojiganga La garapiña de Cal-

${ }^{15}$ Manuel Poggio Capote: "El desfile de la Pandorga en la bajada de la Virgen de las Nieves", Crónicas de Canarias, 12, 2016, pp. 443-466.

${ }^{16}$ Fátima Bethencourt Pérez: La danza de los enanos, Santa Cruz de Tenerife, Caja Canarias Obra social y Cultural, 2015, p. 29. La autora indica que la primera referencia histórica a la Pandorga "se remonta a los festejos para conmemorar el nacimiento de Felipe IV (14-4-1605) en la ciudad de Valladolid".

${ }^{17}$ José Ramón López de los Mozos Jiménez, Juan Manuel de Cózar del Amo: "La Pandorga de Semana Santa en Auñón (Guadalajara)", Revista de Folklore, 393, 2014, pp. 35-42.

${ }^{18}$ María Asunción Flórez Asensio: Teatro musical cortesano en Madrid durante el siglo XVII: Espacios, intérpretes y obras, tesis doctoral, Universidad Complutense de Madrid, 2004, p. 810 (https://eprints.ucm. es/5131/1/T27680.pdf, consulta 22-7-2019).

${ }^{19}$ Ibid., p. 806, n. 764.

${ }^{20}$ Ibid., p. 802.

${ }^{21}$ Luis Antonio González Marín: "Fin de fiesta", DMEH..., vol. 5, pp. 141-142: "La música estridente y poco o nada sujeta a las normas de la composición es otra constante en las mojigangas (este género de música recibe el nombre de pandorga, que, según Covarrubias, 'es una consonancia medio alocada y de mucho ruido que resulta de variedad de instrumentos'), junto con la escenificación de bailes grotescos de máscaras, como el de matachines (composiciones con este título se encuentran frecuentemente en los libros de guitarra española del s. XVII)". 
derón incluyen la pandorga como fin de fiesta. En el entremés se señala:"Salen todos esta postrera vez con cañas y banderillas de papel, coronas y capotillos pintados, como muchachos que van a los gallos, y con varios instrumentos de la pandorga"; en La garapiña se indica: "Con esta repetición y todos con instrumentos de pandorga, acaban bailando"22. En la zarzuela Los celos hacen estrellas (1672), de Juan Vélez de Guevara, se menciona la pandorga comparándola con la mojiganga y se indica que la primera era más ruidosa:

BORJA: Buscando ando una pandorga.

ESCAMILLA:Yo busco una mojiganga.

BORJA: La pandorga hace mas ruido $[\ldots]^{23}$.

Cuadro 2. Instrumentos de pandorga mencionados en crónicas de ceremonias festivas, documentos teatrales y letras de villancicos

\begin{tabular}{|l|l|l|}
\hline Percusión & Viento & Cuerda \\
\hline Almirez & Chirimía & Arpa \\
Carraca & Dulzaina & Bandurria \\
Castañuelas & Flauta & Lira \\
Cencerro & Órgano de perros & \\
Esquileta & Silbato & \\
Matraca & Trompeta & \\
Pandereta & & \\
Pandero & & \\
Sonajas & & \\
Tamboril & & \\
Tarrañuelas & & \\
Zambomba & & \\
Zampoña & & \\
\hline
\end{tabular}

Asimismo, la Mojiganga de Florinda, obra "de un ingenio de Sevilla" conservada en un manuscrito de la Biblioteca Nacional de España, finaliza con una pandorga: $:^{24}$

Moros

[... cese el sarao y cese la mojiganga

$1 .^{\circ}$ yo dejo el caballo

2 yo dejo la lanza

$3 .^{\circ}$ yo largo la yegua

4 y yo aquella adarga
$1 .^{a}$ yo tomo el pandero

2. ${ }^{a}$ y yo las sonajas

3. ${ }^{a}$ yo las castañetas

4 y yo aquesta flauta

Todos y dándole fin al baile

Acabémoslo con pandorga ${ }^{24}$.

${ }^{22}$ María Luisa Lobato (ed.): Calderón de la Barca. Teatro cómico breve, Kassel, Reichenberger, 1989, pp. 443 y 710 .

${ }^{23}$ Juan Vélez de Guevara: Los celos hacen estrellas, J. E. Varey y N. D. Shergold (eds.), Jac Sage (ed. musical), Londres, Tamesis, 1970, p. 123.

${ }^{24}$ Mojiganga de Florinda de un yngenio de Sebilla (MS, siglo XVII), Madrid, Biblioteca Nacional de España, MSS/15351. 
La mojiganga La casa del duende (1716) de José de Cañizares (1676$1759)^{25}$ contiene también un final en pandorga con mención a los instrumentos propios de la misma:

$\begin{array}{cl}\text { Colegial } & \begin{array}{l}\text { Pues ya no hay otro remedio } \\ \text { y el día las circunstancias } \\ \text { trae consigo de alegría } \\ \text { entremos todos en danza. }\end{array} \\ \text { Música } & \begin{array}{l}\text { Pues dale al panderillo } \\ \text { y a las sonajas } \\ \text { y forme nuestra burla } \\ \text { la mojiganga. }\end{array} \\ \text { Coro } \quad \begin{array}{l}\text { Que celebrar tal día } \\ \text { no es cosa impropia } \\ \text { el ser todos figuras } \\ \text { de la Pandorga. Fin }\end{array}\end{array}$

\section{Villancicos de pandorga}

Estas mojigangas y pandorgas eran frecuentes en la representación de los autos sacramentales del Corpus. Por ejemplo, un villancico del poeta y dramaturgo Manuel de León Marchante (1631-1680) publicado póstumamente se titula "Pandorga" y hace referencia a esta como un grupo de "disonantes instrumentos" propio de la fiesta del Corpus que, con motivo del Nacimiento, eran tañidos por pastores para alabar al Niño: la pandorga "hoy se viene al Nacimiento, / para que el Niño la vea"26. Los instrumentos que se mencionan en el villancico son los siguientes: zambomba, tarrañuelas, matraca, bandurria, lira, pandero, sonajas, zampoña, silbato, carraca, cencerro y castañuelas. A lo largo del villancico se juega con el contraste entre la disonancia de los instrumentos y la armonía que propicia el Nacimiento ("porque a Dios alabando, / nada disuena"). En la última sección del villancico se dedica una estrofa a cada instrumento, destacando la zambomba, mencionada también en el estribillo, que "es la que agrada" y "a todos alegra". Según el impreso donde se recoge la letra de este villancico, es uno de los escritos para la Capilla de las Descalzas Reales para su interpretación en los Maitines de Navidad en 1676. La letra del villancico "Pandorga" de Manuel de León Marchante es muy similar a la de otro villanci-

\footnotetext{
${ }^{25}$ José de Cañizares: Mojiganga de la casa del duende (MS, 1716), Madrid, BNE, MSS/14518/4/1, ff. $1 \mathrm{r}-10 \mathrm{r}$.

${ }^{26}$ Manuel de León Marchante: Obras poéticas phostumas, recopilación de Fernando Monge, tomo 2, Madrid, Gabriel del Barrio, 1733, pp. 166-167. Este villancico es mencionado en J. A. Donostia, "Instrumentos de música popular española", p. 148, para ilustrar su definición de pandorga.
} 
co interpretado en la Catedral de Sevilla en los Maitines de Navidad de $1688^{27}$, con música de Diego José de Salazar, maestro de capilla de esa institución desde 1685 y hasta su fallecimiento en $1709^{28}$. El Apéndice de este artículo presenta una comparación de ambos villancicos que podría llevar a atribuir la letra del villancico de Salazar interpretado en Sevilla al mismo poeta. También en la British Library se conserva un pliego de villancicos que incluye uno, "En el portal de Belén", etiquetado como "Pandorga". Se trata del tercero de los villancicos que interpretó la capilla de música de la Catedral de Barbastro (Huesca) bajo el maestrazgo de Manuel Jacinto Navarro la Noche Buena de $1668^{29}$.

La temática de la pandorga en la celebración del Nacimiento aparece ya en uno de los villancicos interpretados en la Catedral de Toledo en la Noche Buena de 1653, cuando era maestro de capilla Tomás Micieces $(1624-1667)^{30}$. Al final del quinto villancico, "Vaya una mojiganga", se

${ }^{27}$ Letras de los villancicos, que se cantaron en los Solemnes Maytines del Nacimiento de nuestro Señor Jesu Christo, en esta nuestra Santa Metropolitana, y Patriarchal Iglesia de Sevilla, este presenta Año de 1688. Compvestos por don Diego Joseph de Salazar, Racionero, y Maestro de Capilla de dicha Santa Iglesia, Sevilla, Juan Francisco de Blas, [1688]. El ejemplar consultado se conserva en Madrid, BNE, VE/1309/55.

${ }^{28}$ Juan Ruiz Jiménez destaca la ingente producción de Diego José de Salazar listada en el inventario realizado entre 1721 y 1724 por José Muñoz Monserrat. Incluía 109 obras en latín y 211 en lengua vernácula; véase Juan Ruiz Jiménez: La librería de canto de órgano: creación y pervivencia del repertorio del Renacimiento en la actividad musical de la catedral de Sevilla, Granada, Centro de Documentación Musical de Andalucía, 2007, p. 25. Véase también Herminio González Barrionuevo et al.: Catálogo de libros de polifonía de la Catedral de Sevilla, Granada, Centro de Documentación Musical de Andalucía, 1994, pp. 698-703 (obras de Salazar incluidas en el libro de polifonía 16 de la Catedral de Sevilla [E.Sc 16]) y 838 (biografía de Salazar). Algunos de los villancicos de Salazar con acompañamiento instrumental se conservan en archivos americanos desde la década de 1960, según Robert Stevenson: Renaissance and Baroque Musical Sources in the Americas, Washington D. C., General Secretariat, Organization of American States, 1970, pp. 65, 178, 218 y 250.

${ }^{29}$ Letras de los villancicos, que se han de cantar en la Santa Iglesia Cathedral de Barbastro, la Noche del Nacimiento de Nuestro Señor Iesu Christo este año de 1668 siendo Maestro de Capilla Manuel Iacinto Navarro. Ofrecidas A los muy Ilustres Señores Dean, y Cabildo de dicha Santa Iglesia, Huesca, Iuan Francisco de Larumbe, 1668. Véase Álvaro Torrente, Miguel Ángel Marín: Catálogo descriptivo de pliegos de villancicos. Pliegos de villancicos en la British Library (Londres) y la University Library (Cambridge), Kassel, Reichenberger, 2000, pp. 7-8. El pliego se conserva en Londres, British Library, 11450.dd.8(51). Manuel Jacinto Navarro ocupó el magisterio de capilla de la Catedral de Barbastro entre 1661 y probablemente 1671; véase Susana Flores: "Barbastro, Música en la Catedral de", Gran Enciclopedia Aragonesa. Apéndice III, Zaragoza, Aragonali, 1997, p. 57. Podría ser el mismo Manuel Jacinto Navarro que ocupó el puesto de organista en la Catedral de Jaén entre 1671 y 1685 y, desde 1686, en la Catedral de Cádiz; véase Pedro Jiménez Cavallé: "Navarro (I)", DMEH..., vol. 7, p. 988. Entre los Apuntes biográficos de diversas personas, cartas y otros documentos, recopilados por Francisco A. Barbieri se menciona a Manuel Jacinto Navarro, organista de Barbastro, 1671; Madrid, BNE MSS/14038/1/97, MSS/14038/1/4, MSS/14038/1/34-68.

${ }^{30}$ Álvaro Torrente cifra en 345 los villancicos de Tomás Micieces que se conservan. Véase Á. Torrente: "Miciezes [Micieces, Miçiezes, Micieres], Tomás", Grove Music Online (https://www.oxfordmusiconline. com/grovemusic/view/10.1093/gmo/9781561592630.001.0001/omo-9781561592630-e-0000018605, consulta 3-9-2019). 
anuncia: "Que una Pandorga al Niño / le hagamos quiero, / pues si a uno celebramos, / a una cantemos" (véase Ilustración 2) ${ }^{31}$. Asimismo, en el último de los villancicos interpretados en la Catedral de Toledo en la Navidad 1668, "Con punta de sacristán”, se introduce la pandorga en el estribillo:

Salgan, salgan

las gaitillas, las azudas, las pandorgas y las danzas, los valientes, los negrillos, los herreros, las campanas ${ }^{32}$.

La tercera copla clarifica que con "pandorga" se está aludiendo a un con-
junto de instrumentos:

Con música de instrumentos

a este Nacimiento salga

la pandorga y podrá bien

donde figuras no faltan.

Pandorga:Vaya de fiesta, que pandorga nos pide

la Nochebuena.

\footnotetext{
${ }^{31}$ Villancicos, que se cantaron la noche de el Nacimiento de nuestro Señor Iesu Christo, en la santa Iglesia de Toledo, Primada de las Españas, este año de 1653, Toledo, Francisco Calvo, 1653. El pliego consultado se encuentra en Madrid, BNE, VE/88/19. Sobre este villancico, "Vaya una mojiganga", véase Josep Pujol i Coll: Els vilancets "de negre" al segle XVII, 2 vols., tesis doctoral, Universitat Autònoma de Barcelona, 2015, vol. 1, pp. 125-152. Otro villancico con alusiones a la pandorga se menciona en Alejandro Luis Iglesias: "17 pliegos del XVII en la catedral de Palencia", Actas del III Congreso de Historia de Palencia: 30, 31 de marzo y 1 de abril de 1995, 4 vols. María Valentina Calleja González (coord.), Palencia, Diputación Provincial de Palencia, 1995, vol. 4, pp. 157-188; 161.

${ }^{32}$ Letras de los villancicos de Navidad, que se han de cantar en la Santa Iglesia Toledo Primada de las Españas, este año de 1668, Toledo, Francisco Calvo, 1668.
} 


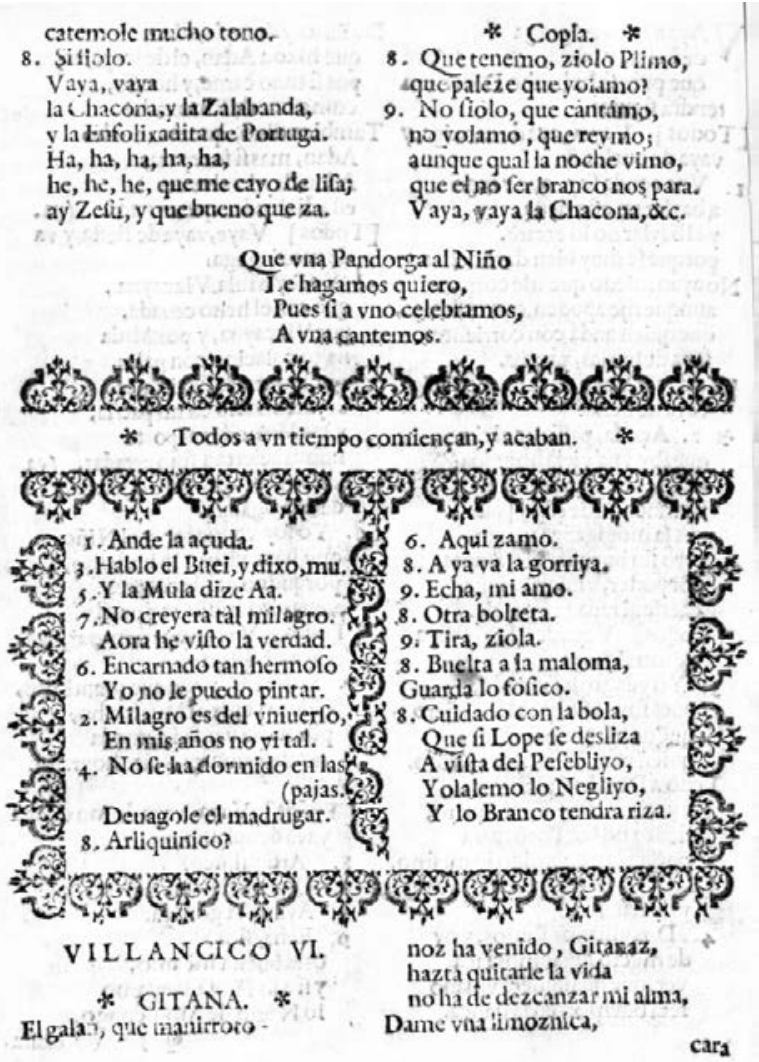

Ilustración 2. Final del quinto de los Villancicos, que se cantaron la noche de el Nacimiento de nuestro Señor Iesu Christo... Toledo, Francisco Calvo, 1653 (BNE, VE/88/19)

Las pandorgas eran típicas no solo del Corpus, sino también de la noche de San Juan. Por ejemplo, Casiano Pellicer indica que una de estas pandorgas, compuestas "de varios instrumentos vulgares, como tamboriles, panderetas, sonajas y castañuelas", sustituyó a la música de guitarras que habitualmente daba inicio a la representación teatral en las fiestas que ofreció el Conde Duque de Olivares a los Reyes en la noche de San Juan de 1631 en los jardines del Conde de Monterrey en Madrid ${ }^{33}$.

${ }^{33}$ Casiano Pellicer: Tratado histórico sobre el origen y progreso de la comedia y del histrionismo en España, José María Díez Borque (ed.), Barcelona, Labor, 1975, p. 126; citado en M. A. Flórez Asensio, Teatro musical cortesano en Madrid durante el siglo XVII..., p. 810, n. 781. 
No se tiene constancia de la conservación de la notación musical de estos villancicos para conocer el modo en que compositores como Diego José de Salazar, Manuel Jacinto Navarro o Tomás Micieces representaban (o no) en sus composiciones polifónicas los sonidos de la pandorga. Sí disponemos, no obstante, de dos ejemplos musicales más tempranos vinculados a la pandorga, ambos datados en 1615 y que son obra del compositor y organista portugués Gaspar Fernandes (c. 1570-1629), activo en las catedrales de Évora, Guatemala y Puebla. Se trata de la ensalada a seis voces "Cuando bajó Dios al suelo" y de una pieza sin texto a tres voces (tiple, alto y tenor) titulada "Principio de la pandorga". Ambas piezas se conservan en el manuscrito autógrafo localizado en el Archivo Histórico de la Arquidiócesis de Antequera-Oaxaca y conocido sobre todo como "Cancionero Musical de Gaspar Fernandes" 34 . Incluye en torno a trescientas piezas - principalmente chanzonetas y villancicos- compuestas por Fernandes para la Catedral de Puebla entre 1609 y $1616^{35}$. El manuscrito se encuentra en mal estado de conservación, especialmente en el vuelto de los folios. El fragmento de la ensalada en el que se hace referencia a la pandorga es el siguiente:

[...] El sacristán, el barbero,

el cura y el alguacil,

hicieron una pandorga

que fue cosa de decir.

Porque los instrumentos

sonaban así:

el atabal

${ }^{34}$ Para un estado de la cuestión reciente acerca de los estudios que han tomado como objeto este manuscrito, véase Omar Morales Abril: "Gaspar Fernández: su vida y obras como testimonio de la cultura musical novohispana a principios del siglo XVII", Enseñanza y ejercicio de la música en México, Ciudad de México, Centro de Investigaciones y Estudios Superiores en Antropología Social/El Colegio de Jalisco/ Universidad de Guadalajara, 2013, pp. 71-125. Para una edición de parte del manuscrito (con las piezas datadas entre 1609 y 1610), véase Aurelio Tello: Cancionero musical de Gaspar Fernandes. Tomo primero [Tesoro de la Música polifónica en México 10], La Habana, Fondo Editorial Casa de las Américas, 2001. A. Tello: Archivo musical de la catedral de Oaxaca: antología de obras, México, Cenidim, 1990, no incluye las dos piezas vinculadas a la pandorga. "Cuando bajó Dios al suelo" y "Principio de la pandorga" no han sido editadas hasta el momento. Agradezco a Javier Marín López el que me haya mostrado imágenes de los folios del manuscrito original correspondientes a estas dos piezas.

${ }^{35}$ Según R. Stevenson: Renaissance and Baroque Musical Sources in the Americas, p. 203, la ensalada se encuentra entre los folios $249 \mathrm{v}$ y $250 \mathrm{r}$ y el trío entre los folios $252 \mathrm{v}$ y $253 \mathrm{r}$. Según A. Tello: Archivo musical de la catedral de Oaxaca: Catálogo, Ciudad de México, Cenidim, 1990, pp. 79-80, la ensalada se ubica entre los folios 250v y $251 \mathrm{r}$ y el trío en el folio $253 \mathrm{v}$. Las imágenes del manuscrito original a las que he tenido acceso presentan, efectivamente, una doble foliación. Sobre la letra de la ensalada, véase también Mariana Masera: "Canciones tradicionales, enigmas, y canciones de brujas en un manuscrito novohispano del siglo XVII", Lyra mínima oral: los géneros breves de la literatura tradicional. Actas del Congreso Internacional celebrado en la Universidad de Alcalá, 28-30 octubre 1998, Carlos Alvar Ezquerra (coord.), Alcalá de Henares, Universidad de Alcalá, 2001, pp. 169-178; 174. 


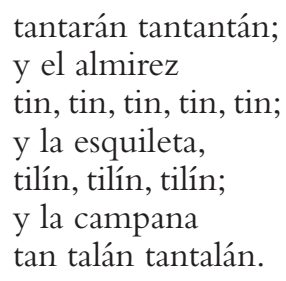

Por tanto, esta pieza introduce de nuevo la idea de pandorga en el texto en el sentido de una interpretación ruidosa con un grupo de instrumentos principalmente de percusión, como también lo hacían los villancicos analizados anteriormente. La música que acompaña a este fragmento se caracteriza por el ritmo ostinato con repeticiones de notas breves al unísono, seguramente imitando los instrumentos de percusión que se mencionan en el texto. La segunda pieza, "Principio de la pandorga", no tiene texto y podría representar en la propia música los sonidos de la pandorga o estar inspirada en ellos. Robert Stevenson considera que las piezas sin texto del manuscrito de Fernandes podrían ser para órgano, mientras que Aurelio Tello argumenta que se trata de piezas para ser cantadas o tocadas por ministriles ${ }^{36}$. Entre la ensalada y esta segunda pieza se insertan en el manuscrito tres piezas sobre el Nacimiento ("No lloréis en naciendo" "Si a Belén Carrillo vas" y "Oh qué gozo tan profundo"), por lo que el "Principio de la pandorga" podría relacionarse con ellas y haberse interpretado en el mismo contexto que estas piezas vocales propias de la celebración de la Noche Buena. La pieza se caracteriza por el cambio de indicación de mensuración, de binaria a ternaria, y por la repetición de notas rápidas al unísono en la parte final, produciendo un efecto similar al que encontrábamos en la ensalada. En cualquier caso, es difícil identificar cuál era la idea de pandorga que tenía Gaspar Fernandes, puesto que, además de como un conjunto de instrumentos ruidosos, la pandorga se ha identificado como un baile de los que aparecen en fuentes teatrales, caracterizado por el "ruido estrepitoso y desconcertado" de instrumentos musicales "populares y ruidosos", según Cotarelo y Mori ${ }^{37}$. Por ejemplo, la pandorga se menciona junto al villano y la danza de cascabel en un romance pastoril de Alonso de la Torre publicado entre el material preliminar de los Discursos sobre el arte danzado (1642) de Juan de Esquivel:

${ }^{36}$ A. Tello: Archivo musical de la catedral de Oaxaca..., p. 16. Interpretaciones de esta pieza han sido grabadas por el Ensemble Elyma en Musique à la Cathédrale d'Oaxaca: Oeuvres de Gaspar Fernandes E Manuel de Sumaya (CD, Mis, 2017) y, en un arreglo para guitarra barroca, por La Fontegara en Tente en el Ayre. Música barroca de la Nueva España, CD, Clásicos Mexicanos, 2000.

${ }^{37}$ Emilio Cotarelo y Mori: Colección de entremeses, loas, bailes, jácaras y mojigangas, Madrid, Bailly Bailliére, 1911, p. ccxciv. 
El villano, y la pandorga

y danza de cascabel

todos juntos en malora

arredro vayan, Amén ${ }^{38}$.

En El diablo cojuelo (1641),Vélez de Guevara mencionaba la pandorga entre una serie de danzas: "[...] yo traje al mundo la zarabanda, el déligo, la chacona, el bullicuzcuz, las cosquillas de la capona, el guiriguirigay, el zambapalo, la mariona, el avilipinti, el pollo, la carretería, el hermano Bartolo, el carcañal, el guineo, el colorín colorado; yo inventé las pandorgas, las jácaras, las papalatas, los comos, las mortecinas, los títeres, los volatines, los saltambancos, los maesecorales y, al fin, yo me llamo el Diablo Cojuelo" ${ }^{39}$. Más adelante, vuelve a utilizar el término en relación a un conjunto de instrumentos:"Con esto, salieron del soñado (al parecer) edificio, y enfrente de él descubrieron otro, cuya portada estaba pintada de sonajas, guitarras, gaitas zamoranas, cencerros, cascabeles, ginebras, caracoles, castrapuercos, pandorga prodigiosa de la vida, y preguntó don Cleofás a su amigo qué casa era aquella que mostraba en la portada tanta variedad de instrumentos vulgares [...]"

La pandorga también aparece entre las danzas que se interpretaron con motivo de la entrada de Mariana de Austria en Madrid en 1649, junto con otros entretenimientos predominantemente burlescos, aunque en el manuscrito que recoge los datos y gastos de las danzas no se ofrece descripción de esta danza de la pandorga en particular, que tuvo lugar el 18 de abril ${ }^{41}$. En su Entremés de los instrumentos (1663), donde Pedro Calderón de la Barca asociaba cada instrumento a un tipo de danza, se relacionaban las sonajas con la pandorga:

[Las sonajas]

Este es gusto de los blancos, regocijo de los negros, socorro de villancicos, de las pandorgas, estruendo, chillido de portugueses $[\ldots]^{42}$.

${ }^{38}$ Fragmento de un romance pastoril de Alonso de Torres, incluido entre el material preliminar de Juan de Esquivel Navarro: Discursos sobre el arte del dançado y sus excelencias, Sevilla, Juan Gómez de Blas, 1642 , s. f.

${ }^{39}$ Luis Vélez de Guevara: El diablo cojuelo, Madrid, Imprenta Real, 1641, f. 5 v.

${ }^{40}$ Ibid., f. $27 \mathrm{v}$.

${ }^{41}$ David Sánchez Cano: "Dances for the Royal Festivities in Madrid in the Sixteenth and Seventeenth Centuries", Dance Research: The Journal of the Society for Dance Research, 23, 2, 2005, pp. 123-152; 138. Este trabajo toma como fuente el manuscrito conservado en Madrid, Archivo de la Villa, ASA 2-58-13. Los datos referentes a la danza de la pandorga se encuentran en los ff. 233r-234v.

${ }^{42}$ Pedro Calderón de la Barca: Entremeses, jácaras y mojigangas, Evangelina Rodríguez, Antonio Tordera (eds.), Madrid, Castalia, 1983, pp. 227-239; 236-237. 
Asimismo, en la mojiganga de La Manzana de Francisco Antonio de Monteser, la pandorga se presenta como una mezcla de pandero, sonajas, castañetas y flauta, y en El mundi nuevo deVicente Suárez de Deza se caracteriza la pandorga por la conjunción de diferentes instrumentos en la repetición de los estribillos entonados por los danzantes: tamborilillos (tañidos por los negros), tamboril (tocado por el portugués) y dulzainas (que tocan los valencianos $)^{43}$.

\title{
La pandorga como serenata
}

Más allá de su vinculación con el teatro, las celebraciones del Corpus y el baile, la pandorga tenía, como advertía Cotarelo y Mori ${ }^{44}$, un origen anterior al de la mojiganga y ya Lope de Vega en su comedia El alcalde mayor (1604-1612) vinculaba la pandorga a un tipo de serenata:

\author{
Oigas en Salamanca \\ cantaletas famosas de estudiantes, \\ a la lechuza blanca \\ al búho, y a las grullas vigilantes \\ murciégalos, mochuelo, \\ endechas en murallas, y arroyuelos. \\ En esta ciudad vayas, \\ pandorga, y tenerías en Sevilla, \\ y por entrambas playas, \\ hasta llegar a la contraria orilla, \\ voces que con extremos \\ canten al son del agua, y de los remos. \\ En Galicia panderos, \\ en Portugal tambores, y sonajas, \\ en Madrid pasteleros \\ que de las once arriba se hacen rajas, \\ y nunca te perfumen, \\ ni con su liquidámbar te sahúmen ${ }^{45}$.
}

\footnotetext{
${ }^{43}$ Catalina Buezo: La mojiganga dramática: de la fiesta al teatro, Kassel, Reichenberger, 2005, vol. 2, pp. 109, n. 25; 323-336 (La manzana); y 340-357 (El mundi nuevo). Sobre Vicente Suárez de Deza, véase Esther Borrego Gutiérrez: Un poeta cómico en la corte: vida y obra de Vicente Suárez de Deza, Kassel, Reichenberger, 2002.

${ }^{44}$ E. Cotarelo y Mori: Colección de entremeses, loas, bailes, jácaras y mojigangas, p. ccxciv. Véase también Gabriel María Vergara Martín: Cuatro mil palabras y algunas más, de uso frecuente, no incluidas en el Diccionario de la Real Academia Española, Madrid, s.n., 1925, p. 145: "Equivale a serenata en algunas regiones españolas".

${ }^{45}$ Lope de Vega Carpio: Trezena parte de las comedias de Lope de Vega Carpio, Madrid, por la viuda de Alonso Martín, 1620, ff. 7v-8r.
} 
También en el El amante agradecido (1618) el autor mencionaba la pandorga con el sentido de serenata:

\author{
Pandorgas y pataratas, \\ matracas y cantaletas, \\ porque son los más poetas \\ y andan las musas baratas. \\ Anteanoche una pandorga, \\ Julia, a una vecina dio, \\ que presumo que se oyó \\ desde la ciudad de Astorga [...]. \\ Sale una cuadrilla con varios instrumentos y pandorga y diga la música: \\ Los que venimos a darle \\ esta matraca y pandorga, \\ de en casa del desengaño \\ hemos sacado las coplas ${ }^{46}$.
}

En su diccionario etimológico, Joan Coromines data el término pandor$g a$ en el siglo XVII y lo define como una "serenata ruidosa y desconcertada" que parece derivar del verbo pandorgar, que significa "dar una serenata" y procede del latín pandoricare:

PANDORGA, princ. s. XVII, "serenata ruidosa y desconcertada". Parece deriv. de un verbo *pandorgar "dar una serenata", procedente de un lat. vg. *PANDORICARE, deriv. de PANDORIUM "bandurria”, "pandero", vid. PANDERO; el oc. ant. mandurgar "tocar la bandurria" es continuación de una variante del mismo verbo latino. De "serenata" se pasó a "instrumento para darla", princ. s. XVII, y en especial "zambomba", y de ahí, por comparación de forma, a "mujer ventruda", princ. s. XVII, y "panza" 47.

Asimismo, en un vejamen "que se dio en el certamen del Buen Retiro" en 1638, Antonio Coello narra un sueño en el que, junto a Francisco de Rojas y Antonio Solís, subió a unos chirriones y participó en una pandorga con "desconcierto de almireces" y "espantoso ruido, estruendo y gritería":

Estando en esto, nos aguijó D. Juan [Espina]; subieron los demás en los carros, y [Francisco de] Rojas, [Antonio de] Solís y yo en los chirriones, y yendo en el camino, empezó a darle a la pandorga un desconcierto de almireces, de que se empezaron a ir todos con tan espantoso ruido, estruendo y gritería que desperté del susto, y hallándome en mi cama, me hallé muy contento de que hubiese sido burla y sueño todo lo que he dicho ${ }^{48}$.

\footnotetext{
${ }^{46}$ Lope de Vega Carpio: El amante agradecido, Madrid, Alonso Martín de Balboa, 1618, ff. 112v y 127r.

${ }^{47}$ Joan Coromines: Breve diccionario etimológico de la lengua castellana, Madrid, Gredos, 1987 [1961], p. 437.

${ }^{48}$ Antonio Paz y Mélia: Sales españolas; ó, Agudezas del ingenio nacional, Madrid, Tello, 1890, vol. 2, pp. $325-338 ; 338$.
} 


\section{La pandorga en el contexto del ceremonial urbano}

La pandorga como serenata se vinculaba a los estudiantes, como mostraba Lope de Vega en El alcalde mayor, donde se aludía a los estudiantes de Salamanca. Las primeras menciones claras a pandorgas de estudiantes se encuentran, sin embargo, en las relaciones de fiestas, siendo una constante en el ceremonial festivo de beatificación y canonización del siglo XVII. La primera referencia documentada a la pandorga se localiza precisamente en la crónica de Diego de Ocaña (1565-1608), titulada Descripción y relación de fiestas en honor de la Virgen de Guadalupe de Chuquisaca, impresa en Bolivia en 1602:

Después de los toros, entraron en la plaza seis cuadrillas de a seis, de juego de cañas, con el adorno y riqueza de libreas que puedo encarecer; los cuales jugaron las cañas con tanta gracia, que ni los caballos cansaban ni los caballeros, ni la gente se enfadaba, aunque jugaran hasta ahora; porque en esta ciudad hay buenos hombres de a caballo y muy buenos caballos; y con esto los dividió la noche con tanto gusto de todos, que se juntaron para despedir la fiesta aquella noche más de doscientos hombres de pandorga, en que llevaban órgano y todos los demás instrumentos músicos curiosos y deleitables que se pudieron hallar en la ciudad; y con ellos los cantores de la iglesia mayor, cantando a las esquinas de las calles tonadas con tanta gracia, que nunca se ha visto cosa semejante en esta tierra ${ }^{49}$.

También una procesión celebrada en Lisboa, desde la catedral a la iglesia de São Domingos, el 20 de septiembre de 1619 con motivo de la visita de Felipe III a la ciudad estuvo encabezada por danzas y hubo "instrumentos de pandorga": "no fueron de menos gusto y contento tantas arpas, rabelillos, violones, vihuelas, panderillos, morteretes, folías, sonajas, e instrumentos de pandorga, que en todas fueron más de veinte danzas, unos cantando, y otros bailando"

Si los artífices de la pandorga en honor de la Virgen de Guadalupe de Chuquisaca eran "hombres" y en el caso de la procesión de Lisboa no se explicita quiénes tocaban los instrumentos de pandorga, en las relaciones de las fiestas de beatificación de Ignacio de Loyola, fundador de la Compañía de Jesús, en 1610, se especifica que las pandorgas eran propias de estudiantes ${ }^{51}$. Esta fue una de las primeras beatificaciones que dio lugar a fiestas que se desarrollaron en diferentes lugares de la Europa católica y el Nuevo

\footnotetext{
${ }^{49}$ Diego de Ocaña: Un viaje fascinante por la América Hispana del siglo XVI, Madrid, Studium, 1969, p. 437.

${ }^{50}$ Francisco de Arce: Fiestas reales de Lisboa, desde que el Rey nuestro señor entrò, hasta que saliò, Lisboa, Iorge Rodriguez, 1619, s.f. Con "folías" puede aludirse a las castañuelas, puesto que eran el instrumento utilizado en las folías como baile.

${ }^{51}$ Ascensión Mazuela-Anguita: "La música en el ceremonial jesuita: Granada y las fiestas de beatificación de Ignacio de Loyola, 1610", Música y ceremonial, María José de la Torre Molina, Alicia Carmen Marchant Rivera (eds.), Madrid, Síntesis, 2019, pp. 149-184.
} 
Mundo y sobre las que se publicaron crónicas. Una particularidad de las fiestas en las que los jesuitas ejercían como anfitriones era la participación de sus estudiantes en el ceremonial a través de desfiles y pandorgas con un componente musical, en ocasiones totalmente ajeno a lo devocional. Por ejemplo, en las celebraciones que se hicieron en Madrid con motivo de la beatificación de Ignacio de Loyola, los estudiantes del colegio jesuita participaron sonoramente en la fiesta organizando una pandorga. En la relación se indica que iban disfrazados de manera cómica y que tocaban arpas, trompetas y chirimías:

[Los estudiantes del colegio jesuita participaron] disparando arcabuces y volando cohetes tocando arpas, trompetas y chirimías y otros instrumentos y vestidos con disfraces de mucha gracia y risa, y tocando mucha diversidad de instrumentos músicos como se suele, hicieron una pandorga con la cual fueron por las calles dando gritos y voces S. Ignacio S. Ignacio, duró todo hasta las 10 de la noche, con grandísima alegría $[\ldots]^{52}$.

También en las fiestas celebradas en Salamanca por el mismo motivo, los estudiantes, disfrazados de forma burlesca, participaron sonoramente en la fiesta tocando los mismos instrumentos y, a modo de parodia, "unos órganos de papel":

Iban también aquí diez músicos de varios instrumentos, y de excelentes voces, los cuales cantaron un Romance a propósito, debajo de las ventanas de la Compañía, y estando todos oyendo la música se interrumpió otra de trompetas y atabales, que asomaba por otro lado de la plaza: y era una graciosa máscara a la picaresca: fiesta propia de los estudiantes de Salamanca, miembro tan principal de ella, que como gente que alcanza más de ingenio y gusto que de dineros, no pudiendo hacer sus fiestas con aparatos tan costosos como los más ricos, las solemnizan con ingeniosas y baratas invenciones, a que en todas las fiestas más graves de esta Ciudad se ha dado siempre muy buen lugar. [...] Otro venía en un borrico con sus lacayos delante, y él puesto a caballo al revés, y venía tañendo unos órganos de papel. [...]Y de esta suerte había otras mil figuras ${ }^{53}$.

Como en Madrid y Salamanca, los estudiantes del Colegio de San Pablo de Granada hicieron una pandorga y el cronista menciona que incluso había leyes relativas a los muchos instrumentos "que pide" la pandorga:

52 "Relación de la fiesta de N. S. P. Ignacio que en Madrid se hizo de su beatificación a 15 de nouiembre de 609", Relaciones de actos públicos celebrados en Madrid (1541-1650), Simón Díaz (ed.), Madrid, Instituto de Estudios Madrileños, 1982, pp. 70-71.

${ }^{53}$ Alonso de Salazar: Fiestas que hizo el insigne Collegio de la Compañia de Iesus de Salamanca a la Beatificación del glorioso Patriarca S. Ignacio de Loyola, Salamanca, por la viuda de Artus Taberniel [Susana Muñoz], 1610, f. [8]r-v. 
[...] salió una Pandorga de los estudiantes de nuestras escuelas menores, por ser en su género para parecer, y para ver. Iban delante seis a caballo con sus hachas, tan bien aderezados, y tan bien puestos, que en máscara de más consideración parecieran bien. Seguíanse treinta estudiantes, vestidos de mil modos, diferenciándose unos de otros, y conviniendo todos en ser de risa, y fiesta. Unos iban vestidos de pies a cabeza de caña, otros de cascabeles, otros de botargas, etc. cada uno con su particular instrumento, de los muchos que pide (según sus leyes) la Pandorga. En medio iba un carro, y en la popa del uno como organista, con figura ridícula de un viejo, y un órgano, cuyos cañones eran ocho perros, mayores, y menores en proporción, para que sus aullidos representasen bien la música de este instrumento, como lo hicieron mal de su grado. Iban asidos en una collera de palo, y las teclas, que eran de lo mismo, asentaban sobre sus pechos, y por tener al cabo cada una púa de hierro los lastimaba muy bien, o muy mal, como lo decían los aullidos que daban. Estas teclas estaban dispuestas de manera, que el organista las tocaba con facilidad, y a punto, y hacíalo cuando callaban los demás instrumentos $[\ldots]^{54}$.

El desfile de Granada incluía, por tanto, un órgano de perros con un mecanismo espeluznante que recuerda al novedoso órgano de gatos que, según describe el cronista Juan Cristóbal Calvete, presenció Felipe II cuando visitaba a su padre en Bruselas en 1549:

Luego pasó una música de extraña manera e invención.Venía un mozo en figura de oso asentado sobre un carro tañendo unos órganos, en que estaban metidos por de dentro en lugar de las flautas gatos vivos, y por buena orden y artificio sacaban todos las colas altas a fuera de tal suerte, que tocando el oso el órgano tiraba de las colas a los gatos en debida proporción y medida a unos mucho, y a otros poco, y a otros medianamente a su compás, y sintiéndose los gatos tirar por las colas aullaban cada uno conforme cómo se dolía, y hacían con sus aullidos altos y bajos una música bien entonada, que era cosa nueva y mucho de ver ${ }^{55}$.

Los jesuitas Athanasius Kircher y su asistente Gaspar Schott describirían este instrumento en sus escritos (Ilustración 3a). En la Musurgia universalis (1650) Kircher había representado la creación del mundo en un grabado titulado "armonía del nacimiento del mundo", utilizando un órgano de seis registros correspondientes a los seis días de la creación y considerando a Dios como el máximo organista ${ }^{56}$. En el siglo XIX, aparecieron ilustraciones

\footnotetext{
${ }^{54}$ Relación de la fiesta que en la beatificación del B. P. Ignacio fundador de la Compañía de Iesvs, hizo su Collegio de la Ciudad de Granada, en catorze de Febrero de 1610. Con el sermón que en ella predicó el Señor Don Sancho Davila y Toledo Obispo de Iaen. Dedicada al Señor Marqves de Velada, Sevilla, En casa de Lvys Estupiñan, 1610, f. 30r-v.

${ }^{55}$ Juan Cristóbal Calvete de Estrella: El felicissimo viaie d'el Poderoso Principe don Phelippe, hijo d'el Emperador don Carlos Quinto Maximo, desde España à sus tierras dela baxa Alemaña, con la descripcion de todos los Estados de Brabante y Flandes: escrito en quatro libros, Amberes, En casa de Martin Nucio, 1552, f. 77r.

${ }^{56}$ Athanasius Kircher: Musurgia universalis sive artis magnae consoni et disoni, Roma, Ex Typographia Haeredum Francisci Corbelletti, 1650, vol. 2, lámina "Harmonia nascentis mundi", situada entre las pp. 366 y 367. Véase, entre otros estudios sobre este libro, Tiziana Pangrazi: La Musurgia Universalis di Athanasius Kircher: contenuti, fonti, terminologia, Florencia, Olschki, 2009.
} 
satíricas con órganos de gatos e incluso de cerdos, que se suelen considerar instrumentos hipotéticos que no llegaron a llevarse a la realidad (Ilustración $3 b)$. La documentación de Granada indica que podrían haberse materializado en el contexto de la pandorga y no ser instrumentos puramente imaginarios.

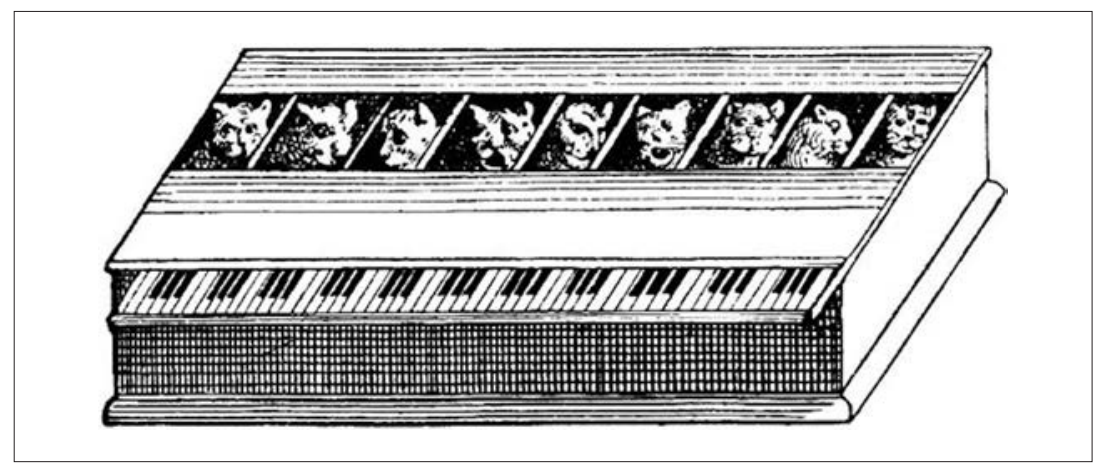

Ilustración 3a. Lámina incluida en Gaspar Schott: Magia universalis naturae et artis, Würtzburg, 1657, Parte 2, Libro 6, Pragmatia 2, "Felium Musicam exhibere"

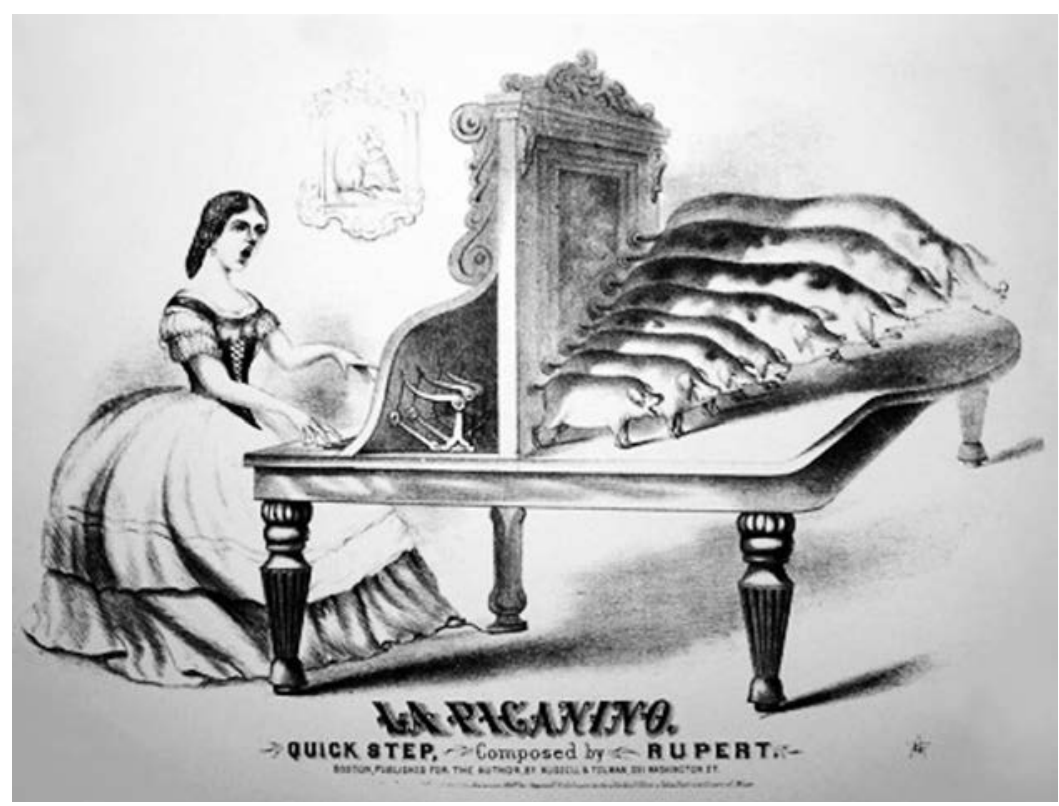

Ilustración 3b. Litografía en la portada de la partitura La piganino. Quick Step, compuesta por Rupert y publicada en Boston, Russell E Richardson, 1867 
La Compañía de Jesús se erigió en el contexto de la Contrarreforma y destacó por sus métodos de control ideológico ${ }^{57}$. La música desempeñaba un rol fundamental en el ideario jesuita, como un modo de estrechar lazos con la comunidad local, y también era esencial en la vida cotidiana de sus colegios $^{58}$. La detallada descripción del órgano de perros y el desfile de estudiantes en la crónica de Granada muestra la integración de elementos sonoros totalmente ajenos a la devoción en el ceremonial festivo por la beatificación de Ignacio de Loyola. La polisemia del término pandorga en general y en sus acepciones musicales en particular-como serenata, conjunto de instrumentos ruidosos, danza y fin de fiesta en representaciones teatrales- muestra la importancia del análisis en profundidad de fuentes no musicales para vislumbrar aspectos de la cultura musical a inicios de la Edad Moderna. Aunque carecemos de su plasmación escrita en notación musical, la música de tradición oral de la pandorga debió formar parte fundamental de la sonoridad del ceremonial urbano. El rol de las pandorgas de estudiantes en este ceremonial era sin duda la intensificación de la celebración y la inclusión de elementos ajenos a lo secular en la fiesta, de modo que todos los sectores de la sociedad se sintieran identificados con la celebración. Estas pandorgas de estudiantes, que procedían de las serenatas e incluían diversidad de instrumentos musicales y mascaradas como manifestación de alegría y espíritu festivo, seguramente precedieron a y coexistieron con las pandorgas del Corpus, que se incorporaron a los fines de fiesta de géneros teatrales como la mojiganga, y se insertaron temáticamente en los villancicos, sobre todo en los que celebraban el Nacimiento.

\footnotetext{
${ }^{57}$ Véanse, entre otros, Evone Levy: Propaganda and the Jesuit Baroque, Berkeley, Los Ángeles y Londres, University of California Press, 2004; y Julián José Lozano Navarro: La Compañía de Jesús y el poder en la España de los Austrias, Madrid, Cátedra, 2005, p. 27.

${ }^{58}$ T. Frank Kennedy: Jesuits and Music: The European Tradition, 1547-1622, tesis doctoral, University of California at Santa Barbara, 1982; John W. O'Malley: Los primeros jesuitas, Juan Antonio Montero Moreno (trad.), Bilbao, Ediciones Mensajero; Santander, Sal Terrae, 1993, p. 201; Anna Harwell Celenza, Anthony R. DelDonna (eds.): Music as Cultural Mission: Explorations of Jesuit Practices in Italy and North America, Philadelphia, Saint Joseph's University Press, 2014; y Andrea Bombi: "Águilas canoras: los jesuitas valencianos y la música (1579-1767)", Il Saggiatore Musicale, 22, 2, 2015 , pp. 151-202.
} 


\section{Apéndice}

Comparación del villancico "Pandorga" con letra de Manuel de León Marchante (interpretado en Madrid, 1676) y un villancico con música de Diego José de Salazar (interpretado en Sevilla, 1688)

Villancico "Pandorga" con letra de Manuel de León Marchante interpretado por la capilla de las Descalzas Reales de Madrid en los Maitines de Navidad en $1676^{59}$.

Villancico. Pandorga

\section{Introducción}

La Pandorga, que del Corpus

sirvió en la célebre Fiesta,

hoy se viene al Nacimiento,

para que el Niño la vea.

Unos pastores la tocan,

mostrando, que a un Dios veneran,

disonantes instrumentos,

con acordes reverencias.

Todos entraron en bulla, y alegre una danza ordenan, concertando una armonía

de disonancias diversas.

\section{Estribillo}

La Pandorga del Corpus

a Belén venga,

porque a Dios alabando,

nada disuena:

venga, venga,

porque a Dios alabando,

nada disuena:

venga, venga, y en rudas cadencias,

la zambomba retumbe con la tarrañuela:

retumbe, retumbe, con voces confusas,

matraca, y bandurria,

retumbe, retumbe con liras bastardas,
Villancico [La Pandorga] con música de Diego José de Salazar interpretado por la capilla de la Catedral de Sevilla en los Maitines de Navidad de $1688^{60}$.

Villancico IV

\section{Introducción}

La Pandorga, que otras noches sirvió en populares fiestas al Nacimiento, se viene para que el Niño la vea.

Todos entraron en bulla, y alegre esta Fiesta ordenan, concertando una Pandorga, que toda la Villa alegra.

\section{Estribillo}

La Pandorga, zagales, a Belén venga, porque a Dios alabando nada disuena;

venga, venga,

y en rudas cadencias,

la zambomba retumbe, conlá, conlá, conlá tarañuela; retumbe, retumbe, con voces confusas, matraca, y bandurria; retumbe, retumbe, con liras bastardas,

\footnotetext{
${ }^{59}$ M. de León Marchante: Obras poéticas phostumas, tomo 2, pp. 166-167.

${ }^{60}$ Letras de los villancicos, que se cantaron, $\mathrm{f}$. [3r-v].
} 
pandero, y sonajas;

retumbe, retumbe, con ecos villanos,

zampoña, y silbato;

retumbe, retumbe con sones groseros,

carraca, y cencerro;

retumbe, retumbe, que al Niño le alegran,

a quien la Pandorga le diga por fiesta,

zambomba, que bulle, zambomba, que suena,

matraca, bandurria, pandero,

sonaja, zampoña,

carraca, cencerro, con la tarrañuela

\section{Romance}

La zambomba es la que agrada;

que en una olla resuena, y después de Dios, la olla, es lo que a todos alegra.

La tarrañuela se sigue,

que es propio de Noche Buena,

divertir las colaciones

con algunas castañuelas:

Zambomba, que bulle,

zambomba, que suena,

zambomba, zambomba con la tarrañuela

La matraca es esta noche

la más propia de la fiesta,

siendo siempre las matracas

las que a Maitines despiertan.

La bandurria en este gozo

pase por dulce vihuela,

que para Dios todo es uno,

cuando en la Fe no disuena:

Zambomba, que bulle, etc. pandero, y sonajas;

retumbe, retumbe, con ecos villanos, zampoña, y silbato; retumbe, retumbe, con sones groseros, carraca, y cencerro;

retumbe, retumbe, que al Niño le alegra, a quien la Pandorga le diga por fiesta:

zambomba, que zumba, pandero, que truena, matraca, que avisa, bandurria, que alienta, sonaja, que bulle, zampoña, que suena, silbato, carraca, cencerro: conlá, conlá, conlá tarañuela.

\section{Coplas}

La zambomba es la que agrada, que en una olla resuena, y después de Dios, la olla es la que a todos alegra. La tarañuela se sigue, que es propio de Nochebuena divertir las colaciones, con algunas castañuelas. Zambomba, que zumba, zambomba, que suena; zambomba, con la tarañuela.

La matraca es esta noche, la más propia de la Fiesta, siendo siempre las matracas las que a Maitines despiertan. El pandero dice al mundo, que hoy es la Pascua primera, que los zagales le tocan con sana paz en la tierra. Matraca, que avisa, pandero, que truena, pandero, con la tarañuela. 
El pandero dice al mundo, que hoy es la Pascua primera, que los zagales le tocan con sana paz en la tierra. La sonaja en forma de Orbe publica con Gloria excelsa, que al nacer Dios, fue sonaja el son de las nueve esferas. Zambomba que bulle, etc.

La zampoña, es armonía del pesebre, pues concuerdan con el heno, y con las pajas, las pastoriles avenas.

El silbato es un enigma de lo que sucedió a Eva, $\mathrm{y}$ que al ver nacido al verbo, silva la antigua culebra:

Zambomba que bulle, etc.

La carraca disonante, alegre al Niño demuestra, que no es la noche del ruido, noche, que olvida las penas. El cencerro, al escucharle, el Dios nacido se alegra, que como es pastor, presume, que le buscan las ovejas. Zambomba, que bulle, etc.
La bandurria en este gozo

pase por dulce vihuela, que para Dios todo es uno, cuando en la fe no disuena. La sonaja en forma de orbe, publica con gloria excelsa, que al nacer Dios fue sonaja el son de las nueve esferas. Sonaja, que bulle, bandurria, que alienta, bandurria, con la tarañuela. La zampoña es armonía del pesebre, pues concuerdan con el heno, y con las pajas las pastoriles avenas. El silbato es un enigma de lo que sucedió a Eva, y que al ver nacido el verbo si va la antigua culebra. Silbato, que zumba, zampoña, que suena, silbato, con la tarañuela. La carraca disonante alegre al Niño demuestra, que no es la noche del ruido noche, que alivia las penas. El cencerro al escucharle el Dios nacido, se alegra, que como es pastor, presume, que le buscan las ovejas. Todos. La Pandorga, zagales, a Belén venga, etc. 